\title{
DIMENSIONAMENTO DE AMOSTRAS PARA MONITORAMENTO DO ÁCARO DA LEPROSE Brevipalpus phoenicis (GEIJSKES, 1939) EM CITROS ${ }^{1}$
}

\author{
MARIANA VILELA LOPES ${ }^{2}$, CARLOS AMADEU LEITE OLIVEIRA ${ }^{3}$, MODESTO BARRETO 3 , \\ JOSÉ CARLOS BARBOSA ${ }^{3}$, FERNANDA MARIA ROSSI ${ }^{4}$
}

RESUMO-O controle do ácaro Brevipalpus phoenicis (Geijskes, 1939), transmissor do vírus da leprose, deve ser realizado quando sua população atinge o nível de ação, obtido pelo monitoramento de sua população, por meio de amostragens. Objetivou-se determinar o tamanho da amostra aceitável para estimar a população do ácaro, para posterior tomada de decisão. O experimento foi realizado na Fazenda Cambuhy, Matão - SP, no ano agrícola 2003-2004. Escolheu-se ao acaso um talhão da variedade Valência, com oito anos de idade, plantada no espaçamento $7 \times 3,5 \mathrm{~m}$, com 2.480 plantas. Nesse talhão, foram inspecionados $1 ; 2 ; 3 ; 5 ; 10$ e $100 \%$ das plantas, o que corresponde a $25 ; 50 ; 74 ; 124 ; 248$ e 2.480 plantas, respectivamente, em caminhamento no sentido das linhas de plantio. Foram amostrados 3 frutos ou, na ausência destes, eram analisados ramos. De acordo com os resultados obtidos, observa-se que a porcentagem de erro na estimativa da média para a porcentagem de frutos com presença de ácaros, quando se amostra apenas $1 \%$ das plantas ( 25 plantas), é de $50 \%$, ou seja, para uma infestação de $10 \%$, a variação da porcentagem de frutos infestados estaria entre 5 e $15 \%$, levando o produtor a subestimar ou a superestimar o nível de infestação, aumentando os gastos com pulverizações desnecessárias ou um controle ineficiente do ácaro. Para que o erro na amostragem fique dentro da situação aceitável, de 20 a $30 \%$ (em média 25\%) de erro, deveriam ser amostradas 105 plantas. Na porcentagem de frutos com mais de 10 ácaros, verifica-se que, para a situação aceitável (20 a 30\%), devem ser inspecionadas 540 plantas.

Termos para indexação: amostragem, ácaro da leprose, citros.

\section{MESURAMENT OF SAMPLES FOR MONITORING THE ACARID OF LEPROUS Brevipalpus phoenicis (GEIJSKES, 1939) IN CITROS}

\begin{abstract}
The control of the flat mite Brevipalpus phoenicis (Geijskes, 1939), vector of the citrus leprous virus, must be done when its population reach the threshold level, estimated by the monitoring the mite population density. The objective of this study was to determine the acceptable sample size for estimating the flat mite population, for later decision. The experiment was realized at the Cambuhy Farm, Matão - SP. It was casually select an orchard of Valência variety, eight years of age, planted in a spacing of $7 \mathrm{x}$ $3.5 \mathrm{~m}$, with 2.480 plants. This orchard was inspected 1,2,3,5, 10 and $100 \%$ of plants, respectively 25, 50, 74, 124, 248 and 2480 plants, by walking in the direction of the planting lines. It was inspected 3 fruits or branch per plant. According to the results, it was observed that the error percentage for estimating the mean percentage of fruits with flat mite, in actual situation of inspection of flat mite leprous in citrus, when it was inspected only $1 \%$ of plants ( 25 plants) the error is $50 \%$, however, for an infestation of $10 \%$ the variation of infested fruits percentage was between 5 and 15\%, leading the farmers to under or super estimate the mite population density, increasing the costs with unnecessary pulverization or an inefficient control of the flat mite. To the error in the sample remains in an acceptable situation ( 20 to $30 \%$ of error), 105 plants must be inspected. In fruits percentage with more than 10 flat mites, it was verified that for the acceptable situation ( 20 to $30 \%$ ), 540 plants must be inspected.
\end{abstract}

Index terms: sampling, flat mite, citrus

A cadeia produtiva da laranja destaca-se no Brasil pela produção de aproximadamente 345 milhões de caixas em uma área colhida de 600 mil hectares, na safra 2003-2004 (AGRIANUAL 2004). O controle fitossanitário dos citros apresenta importância econômica por representar $6 \%$ do total de agrotóxicos consumidos no Brasil, sendo que mais de $60 \%$ dos acaricidas utilizados na citricultura são destinados ao ácaro Brevipalpus phoenicis (Geijskes,1939), que transmite o vírus da leprose, devendo, portanto, ser mantido em baixa população nos pomares (CHIAVEGATO e KHARFAN, 1993; MAGGIONI, 1998; BASSANEZI, 2001). No processo de amostragem para o ácaro da leprose, várias dúvidas são apontadas, uma das quais é se o número de plantas amostrado é suficiente e adequado. Portanto, o controle do ácaro transmissor deverá ser efetuado adequadamente, a partir do momento em que se determine com maior precisão seu nível de infestação, para que se obtenha um controle mais efetivo da leprose. O objetivo deste trabalho foi determinar o tamanho da amostra adequada para o estudo de

(Trabalho 146-06). Recebido em :27-09-2006. Aceito para publicação em: 10-08-2007.

${ }^{2}$ Eng. Agr. MsC (marianavlopes@yahoo.com.br);

${ }^{3}$ Prof. Dr. - FCAV/UNESP, Via de Acesso Prof. Paulo Donato Castellane, s/n, 14884-900 Jaboticabal-SP (modesto@fcav.unesp.br ;

Amadeu@fcav.unesp.br ; jcbarbosa@fcav.unesp.br).

${ }^{4}$ In memoriam.

Rev. Bras. Frutic., Jaboticabal - SP, v. 29, n. 3, p. 671-676, Dezembro 2007 
estimativas de população do ácaro, para posterior tomada de decisão.

O experimento foi realizado na empresa Cambuhy Agrícola Ltda., em Matão-SP, no ano agrícola de 2003-2004, em um talhão com 2.480 plantas da variedade Valência, sobre o porta-enxerto Tangerineria Sunki, com 8 anos de idade, plantadas com espaçamento de $7 \times 3,5 \mathrm{~m}$. Na amostragem de tamanho fixo, também chamada de amostragem convencional, o número de unidades amostrais é fixo e baseia-se num nível de precisão preestabelecido (MARCELINO, 1996). O tipo de agregação de um organismo influi no número de unidades amostrais necessário para estimar a densidade de uma população, com um nível conhecido de confiabilidade (WILSON e ROOM, 1983). De acordo com Ruesink e Kogan (1994), o tamanho da amostra, para um modelo conhecido de distribuição, pode variar de acordo com o nível de confiabilidade utilizado. Pieters e Sterling (1973); Ruesink e Kogan (1994) citam que a amostragem utilizada em pesquisa requer maior precisão e, como conseqüência, maior tamanho de amostra, enquanto, em culturas comerciais, opta-se por um nível menor de confiabilidade, com um tamanho de amostra economicamente viável, de menor custo, apesar de menor eficiência, ao invés de privilegiar-se o tamanho ideal. Com relação à quantidade de unidades amostrais necessárias para avaliar-se a densidade populacional ou os danos provocados pelos insetos, ela é geralmente calculada com base na variância $\left(\mathrm{s}^{2}\right)$ e na média $(\hat{m})$, obtidas de uma amostragem prévia. Essa quantidade de unidades amostrais depende fundamentalmente do nível de precisão desejado, definido em função dos objetivos da amostragem (BIANCO, 1995). O erro-padrão da média fornece uma idéia da precisão da estimativa da média, isto é, quanto menor ele for, maior precisão terá a estimativa da média, e é calculado por:

$$
s(\hat{m})=\frac{s}{\sqrt{n}}
$$

Onde: $s=\hat{m}$ erro-padrão da média; $s=$ desviopadrão; número de dados da amostra.

Segundo Thompson (1992), o número de unidades amostrais para estimarem-se os parâmetros de uma população infinita para um nível de precisão desejado, baseando-se no erropadrão da média, é dado pela fórmula:

$n_{0}=\frac{z^{2} s^{2}}{d^{2}}$

Sendo: $n_{0}=$ número de unidades amostrais para estimar os parâmetros de uma população infinita; $z=$ valor da distribuição normal padrão; $s^{2}=$ variância da amostra; $d=$ erro na estimativa da média.

Para uma população finita, utilizou-se uma correção dada pela fórmula:

$n=\frac{1}{\frac{1}{n_{0}}+\frac{1}{N}}$
Onde: $n=$ número de unidades amostrais para estimar os parâmetros de uma população finita; $n_{0}=$ número de unidades amostrais para estimar os parâmetros de uma população infinita; $N=$ tamanho da população.

O tamanho da amostra para estimar a proporção de uma população que possui certa característica ou atributo, pode ser obtido pelas fórmulas:

$n_{0}=\frac{z^{2} p(1-p)}{d^{2}}$

Onde: $n_{0}=$ tamanho da amostra para estimar os parâmetros de uma população infinita; $z$ = valor da distribuição normal padrão; $d=$ erro na estimativa da média; proporção da população que possui certa característica.

No caso de população finita, utiliza-se a correção:

$$
n=\frac{1}{\frac{1}{n_{0}}+\frac{1}{N}}
$$

Onde: $n=$ tamanho da amostra para uma população finita; $n_{0}=$ tamanho da amostra para uma população infinita; $N=$ tamanho da população.

A amostragem foi realizada com uma lupa de dez aumentos para efetuar a visada do ácaro, além de uma planilha de campo e caneta, para posteriormente ser anotado o número de ácaros observados. Foram fixadas as porcentagens de $1 ; 2 ; 3 ; 5 ; 10$ e $100 \%$ (varredura total do talhão) de plantas a serem inspecionadas. A escolha das plantas a serem examinadas obedeceu ao critério correspondente à porcentagem, isto é, na de $1 \%$, amostrou-se uma a cada 100 plantas; na de $2 ; 3 ; 5$ e $10 \%$, examinou-se 1 a cada $50 ; 33 ; 20$ e 10 plantas, respectivamente. Sendo que, para a porcentagem de $100 \%$, amostraram-se todas as plantas do talhão. Foram inspecionados 3 frutos e, na ausência desses, 3 ramos internos na parte média da planta. Para cada fruto ou ramo inspecionado, foi anotado o número de ácaros presentes numa planilha de campo. Com os resultados obtidos, foram construídos gráficos de dimensionamento da amostra em função do erro na estimativa da média.

De acordo com os dados obtidos nas amostragens de 1; $2 ; 3 ; 5 ; 10$ e $100 \%$ das plantas do talhão, foram calculados as médias, o desvio-padrão e o erro-padrão da média das seguintes variáveis: número de frutos com presença de ácaros (NFA), porcentagem de frutos com presença de ácaros (PFA), número de frutos com mais de 10 ácaros (NF10A) e porcentagem de frutos com mais de 10 ácaros (PF10A) (Tabelas 1;2 e 3). À medida que aumenta o número de plantas amostradas, o erro-padrão da média diminui para todas as variáveis analisadas (Tabela 3). Martinelli et al. (1976) observaram que, em uma amostragem com o número fixo de frutos por planta, o coeficiente de variação foi menor à medida que se aumentou o número de árvores amostradas. Padronizou-se o erro variando de $5 \mathrm{em} 5 \%$ e, a partir desse erro, calculou-se o número de plantas a serem amostradas pelas fórmulas de $n \mathrm{e} n_{0}$, anteriormente descritas. Segundo Southwood (1978), uma precisão com erro-padrão da média em 
torno de $25 \%$ é suficiente para avaliar o dano e tomar a decisão de controle em programas de manejo de pragas. Nas variáveis número de frutos com ácaro (NFA), porcentagem de frutos com ácaro (PFA), número de frutos com mais de 10 ácaros (NF10A) e porcentagem de frutos com mais de 10 ácaros (PF10A), o erropadrão da média foi de $25 \%$, sendo necessária uma amostragem com 46; 103; 277 e 540 plantas, respectivamente, para uma população finita. Com um mesmo número de plantas amostradas, a variável número de frutos com ácaro mostra que, com um menor número de plantas, é possível obter-se menor porcentagem de erro na estimativa da média, sendo que a maior porcentagem de erro obtida foi na variável porcentagem de frutos com mais de 10 ácaros, tornando-se inviável a sua escolha para tomada de decisão sobre o controle do ácaro (Tabela 4). Por questões econômicas, verifica-se que é mais vantajoso avaliar um número maior de plantas, observando apenas a presença ou a ausência do ácaro no fruto, do que contar o número de ácaros por fruto, o que implicaria maior gasto de tempo e, conseqüentemente, aumento da estimativa de erro da média por amostrar-se um menor número de plantas. Adotando-se um erro de $25 \%$ na estimativa da média, pode significar uma variação de erro de 0,73 a 1,27 da média do número de frutos com presença de ácaros. Quanto maior o número de plantas amostradas, menor a porcentagem de erro, reduzindo a sua variação (Tabela 4). Porém, deve ser feito um estudo de viabilidade econômica para a adoção do tamanho ideal da amostra. No caso da porcentagem de frutos com ácaro, uma porcentagem de $25 \%$ de erro na estimativa da média levaria a uma variação de erro de 27,3 a $45,5 \%$ da porcentagem de frutos com presença de ácaros. Nesse caso, o controle do ácaro deveria ser realizado em qualquer situação, pois a média da porcentagem de frutos com presença de ácaros foi superior a $10 \%$, que é o nível de ação adotado pela maioria dos citricultores. Para uma amostragem de $1 \%$ em um talhão de 2.480 plantas, o que corresponde a 25 plantas por talhão, se a porcentagem de frutos com ácaro fosse igual a $10 \%$ dos frutos amostrados, ou seja, uma média de 0,3 fruto infestado por planta e adotando-se um desviopadrão igual a 1 , implicaria uma variação do erro da média de \pm 0,39 . Portanto, para o nível de ação suposto (10\%), a variação do erro seria de $\pm 13 \%$, ou seja, a porcentagem de frutos com ácaro estaria variando entre 0 e $23 \%$. Esses valores podem levar o citricultor a subestimar ou a superestimar o nível de infestação do ácaro, aumentando os gastos com pulverizações desnecessárias no caso de um nível de infestação subestimado, ou um controle ineficiente da praga quando o nível de ação for superestimado. A porcentagem de erro na estimativa da média para a porcentagem de frutos com ácaro, evidenciando a situação atual da amostragem de ácaro da leprose na cultura dos citros, onde o erro cometido, quando se amostra apenas $1 \%$ das plantas (25 plantas), é de $50 \%$, ou seja, para uma infestação de $10 \%$, a variação da porcentagem de frutos infestados estaria entre 5 e $15 \%$. Para que o erro na amostragem fique dentro da situação aceitável, de 20 a $30 \%$ (em média 25\%) de erro, deveriam ser amostradas 105 plantas (Figura 2). Na Figura 1, verifica-se o erro na estimativa da média da porcentagem de frutos com mais de 10 ácaros, onde pode ser observada a situação aceitável, de 20 a $30 \%$ (em média $25 \%$ ) de erro na amostragem do ácaro, o que implicaria inspecionar 540 plantas.

A metodologia atualmente utilizada na prática para amostragem de B. phoenicis, na cultura dos citros, incorre numa porcentagem de erro na estimativa da média em torno de $50 \%$ para a porcentagem de frutos com ácaro, indicando a necessidade de se amostrar maior número de plantas, para que se obtenha um erro na estimativa da média de $25 \%$. O erro obtido em amostragens do ácaro da leprose, na situação atual, induz o produtor a subestimar ou a superestimar o nível de infestação, aumentando os gastos com pulverizações desnecessárias ou um controle ineficiente do ácaro. O parâmetro porcentagem de frutos com mais de 10 ácaros apresentou uma porcentagem de erro na estimativa da média muito alta, tornando a sua utilização inviável.

TABELA 1 - Valores médios do número de frutos com presença de ácaros (NFA), porcentagem de frutos com presença de ácaros (PFA), número de frutos com mais de 10 ácaros (NF10A) e porcentagem de frutos com mais de 10 ácaros (PF10A) para cada unidade amostral (planta).

\begin{tabular}{cccccc}
$\begin{array}{c}\text { AMOSTRA } \\
(\%)\end{array}$ & NPL & NFA & PFA & NF10A & PF10A \\
\cline { 3 - 6 } & & 1,24 & 41,33 & 0,40 & 13,33 \\
\hline 1 & 25 & 1,44 & 48,00 & 0,64 & 21,33 \\
2 & 50 & 1,39 & 46,40 & 0,53 & 17,57 \\
3 & 74 & 1,55 & 51,76 & 0,67 & 22,22 \\
5 & 124 & 1,15 & 38,31 & 0,37 & 12,37 \\
10 & 248 & 1,09 & 36,36 & 0,25 & 8,17 \\
\hline
\end{tabular}

NPL: número de plantas amostradas no talhão. 
TABELA 2 - Valores do desvio-padrão do número de frutos com presença de ácaros (NFA), porcentagem de frutos com presença de ácaros (PFA), número de frutos com mais de 10 ácaros (NF10A) e porcentagem de frutos com mais de 10 ácaros (PF10A) para cada unidade amostral (planta).

\begin{tabular}{cccccc}
\hline \multirow{2}{*}{$\begin{array}{c}\text { AMOSTRA } \\
(\%)\end{array}$} & NPL & NFA & PFA & DESVIO-PADRÃO \\
\cline { 3 - 5 } & & 0,78 & 25,96 & 0,58 & PF10A \\
\hline 1 & 25 & 1,01 & 33,78 & 0,80 & 26,25 \\
2 & 50 & 0,98 & 32,56 & 0,69 & 22,90 \\
3 & 74 & 0,99 & 33,11 & 0,81 & 26,88 \\
5 & 124 & 0,95 & 31,56 & 0,64 & 21,20 \\
10 & 248 & 0,96 & 32,08 & 0,55 & 18,39 \\
\hline 100 & 2480 & & & & \\
\hline
\end{tabular}

TABELA 3 - Valores do erro-padrão da média do número de frutos com presença de ácaros (NFA), porcentagem de frutos com presença de ácaros (PFA), número de frutos com mais de 10 ácaros (NF10A) e porcentagem de frutos com mais de 10 ácaros (PF10A) para cada unidade amostral (planta).

\begin{tabular}{cccccc}
\hline \multirow{2}{*}{$\begin{array}{c}\text { AMOSTRA } \\
(\%)\end{array}$} & NPL & NFA & PFA & NF10A & PF10A \\
\cline { 3 - 6 } 1 & 25 & 2,67 & 0,16 & 5,19 & 0,12 \\
2 & 50 & 3,02 & 0,14 & 4,78 & 0,11 \\
3 & 74 & 2,04 & 0,11 & 3,78 & 0,08 \\
5 & 124 & 2,00 & 0,09 & 2,97 & 0,07 \\
10 & 248 & 0,79 & 0,06 & 2,00 & 0,04 \\
100 & 2480 & 0,16 & 0,02 & 0,64 & 0,01 \\
\hline NPL: número de plantas amostradas no talhão & & & & &
\end{tabular}

TABELA 4 -Valores do erro-padrão da média do número de frutos com presença de ácaros (NFA), porcentagem de frutos com presença de ácaros (PFA), número de frutos com mais de 10 ácaros (NF10A) e porcentagem de frutos com mais de 10 ácaros (PF10A) para cada unidade amostral (planta).

\begin{tabular}{cccccc}
\hline \multirow{2}{*}{$\begin{array}{c}\text { MMOSTRA } \\
(\%)\end{array}$} & NPL & \multicolumn{4}{c}{ ERRO-PADRÃO DA MÉDIA } \\
\cline { 3 - 6 } & 25 & NFA & PFA & NF10A & PF10A \\
\hline 1 & 50 & 24 & 52 & 88 & 131 \\
2 & 74 & 20 & 36 & 62 & 92 \\
3 & 124 & 15 & 23 & 51 & 75 \\
5 & 248 & 11 & 16 & 39 & 58 \\
10 & & & & 27 & 40 \\
\hline
\end{tabular}

NPL: número de plantas amostradas no talhão. 


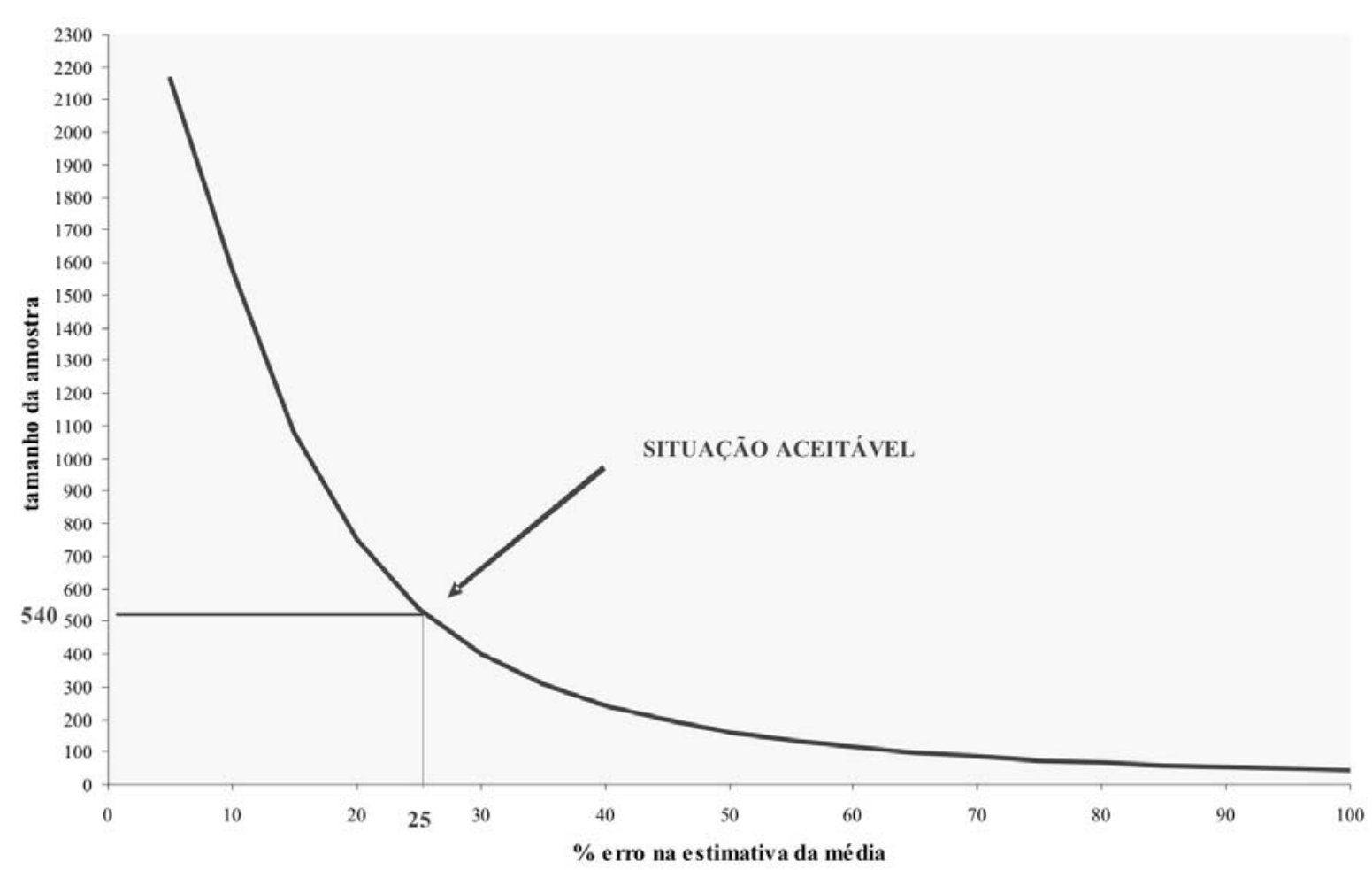

FIGUKA I - rorcentagem ae erro na estımatıva aa meaı para a porcentagem ae rrutos com maıs ae IU acaros.

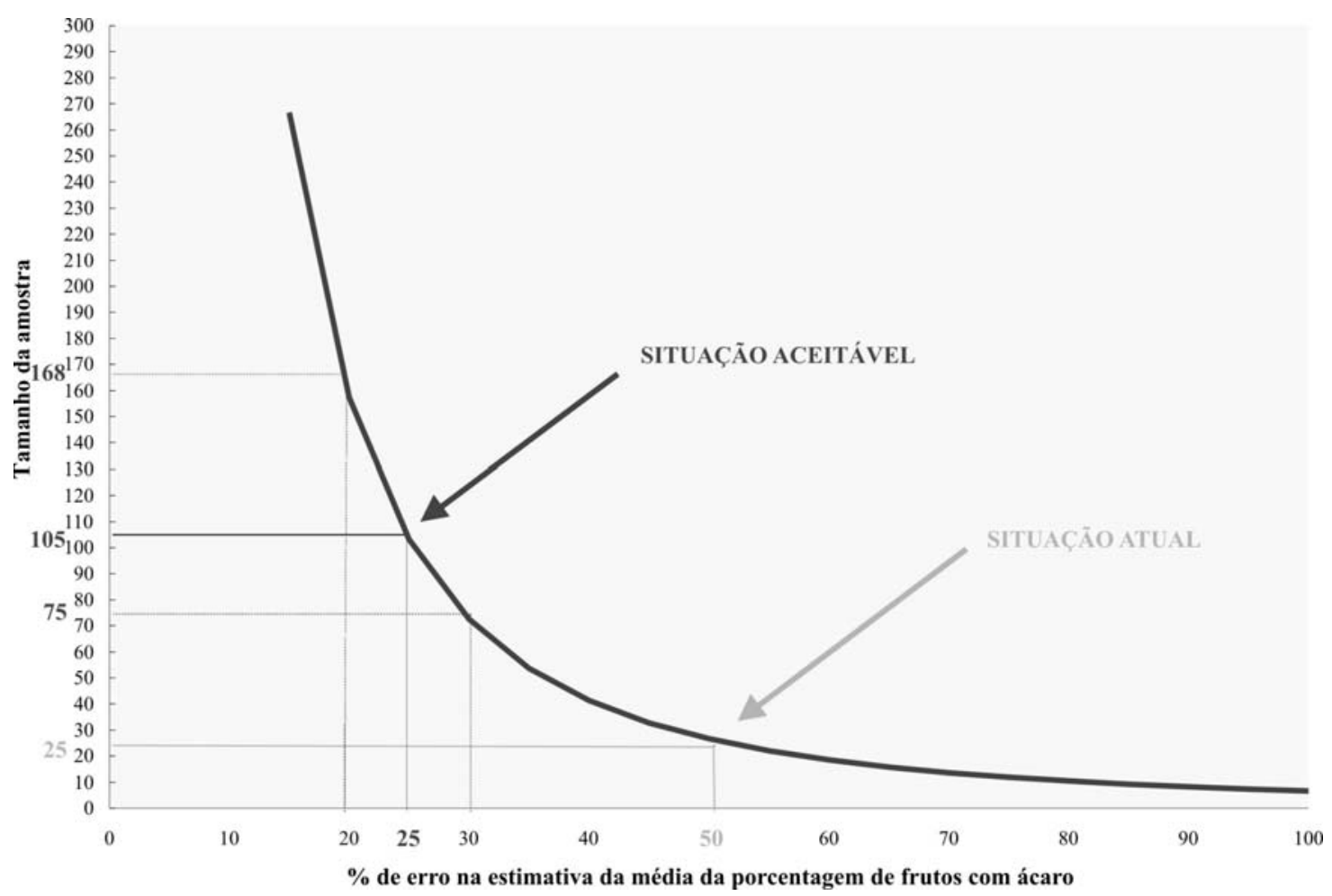

FIGURA 2 - Porcentagem de erro na estimativa da média para a porcentagem de frutos com presença de ácaros. 


\section{REFERÊNCIAS}

AGRIANUAL 2004: Anuário da agricultura brasileira. São Paulo: FNP Consultoria \& Comércio, 2004. p.242.

BASSANEZI, R.B. Aspectos da leprose dos citros. Fitopatologia Brasileira, Brasília, v.26, p.246-247, 2001.

BIANCO, R. Desenvolvimento e validação de planos de amostragem para o manejo da lagarta do cartucho-Spodoptera frugiperda (J. E. Smith, 1797) (Lepidoptera, Noctuidae), na cultura do milho. 1995. 117f. Tese (Doutorado em Entomologia) - Escola Superior de Agricultura “Luiz de Queiroz", Universidade de São Paulo, 1995.

CHIAVEGATO, L.G.; KHARFAN, P.R. Comportamento do ácaro da leprose Brevipalpus phoenicis (G.) (Acari: Tenuipalpidae) em citros. An. Soc. Entomol. Brasil, Londrina, v.22, p.355-359, 1993. MAGGIONE, C.S. Planejamento e custo citrícola. Citricultura Atual, v.1, n.5, p.6, 1998.

MARCELINO, M.C.S. Distribuição espacial e amostragem seqüencial de Enneothrips flavens (MOULTON, 1941) (THYSANOPTERA, THRYIPIDAE) na cultura do amendoim (Arachis hypogaea L.). 1996. 169f. Dissertação (Mestrado em Agronomia)-Faculdade de Ciências Agrárias e Veterinárias, Universidade Estadual Paulista, Jaboticabal, 1996.
MARTINELli, N.M.; OLIVEIRA, C.A.L.; PERECIN, D. Conhecimentos básicos para estudos que envolvam levantamentos de população de Brevipalpus phoenicis (Geijskes), 1939, na cultura de citros. Científica, Jaboticabal, v.4, n.3, p.242-253, 1976.

PIETERS, E.P.; STERLING, W.L. Inferences on the dispersion of cotton arthropods in Texas. Environ. Entomol., College Park, v.2, n.5, p.863-867, 1973.

RUESINK, W.G., KOGAN, M. The quantitative basis of pest management and measuring. In: METCALF, R.L.; LUCKMANN, W.H. (ed.). Introduction to insect pest management. 3 . ed. New York: John Wiley, 1994. p.355-391.

THOMPSON, S.K. Sampling. New York: John Wiley, 1992. 343p. SOUTHWOOD, T.R.E. Ecological methods, with particular reference to the study of insect populations. 2. ed. New York: John Wiley, 1978. 525p.

WILSON, L.T.; ROOM, P.M. Clumpling patterns of fruit and arthropods in cotton with implications for binomial sampling. Envinron. Entomol., Lanham, v.12, p.50-58, 1983. 